\title{
Factors Impacting Physician Referral To and Patient Attendance at Weight Management Programs Within a Large Integrated Health System
}

\author{
Elizabeth R. Pfoh, $P h D, M P H^{7}$ (D) Leslie J. Heinberg, PhD ${ }^{2,3}$, and Michael B. Rothberg, \\ $M D, M P H^{7}$ \\ ${ }^{1}$ Center for Value-Based Care Research, Cleveland Clinic Community Care, Cleveland, OH, USA; ${ }^{2}$ Cleveland Clinic Lerner College of Medicine, \\ Cleveland, OH, USA; ${ }^{3}$ Enterprise Weight Management Center, Cleveland Clinic, Cleveland, OH, USA.
}

BACKGROUND: Identifying which patients receive referrals to and which ones attend weight management programs can provide insights into how physicians manage obesity.

OBJECTIVE: To describe patient factors associated with referrals, which primarily reflect physician priorities, and attendance, which reflects patient priorities. We also examine the influence of the individual physician by comparing adjusted rates of referral and attendance across physicians.

DESIGN: Retrospective cohort study.

PARTICIPANTS: Adults with a body mass index (BMI) $\geq$ $30 \mathrm{~kg} / \mathrm{m}^{2}$ who had a primary care visit between 2015 and 2018 at a large integrated health system

MAIN MEASURES: Referrals and visits to programs were collected from the EHR in 2019 and analyzed in 2019-2020. Multilevel logistic regression models were used to identify the association between patient characteristics and (1) receiving a referral, and (2) attending a visit after a referral. We compared physicians' adjusted probabilities of referring patients and of their patients attending a visit.

KEY RESULTS: Our study included 160,163 adults, with a median BMI of $35 \mathrm{~kg} / \mathrm{m}^{2}$. Seventeen percent of patients received $\geq 1$ referral and $29 \%$ of those attended a visit. The adjusted odds of referral increased $57 \%$ for patients with a BMI 35-39 (versus 30-34) and $32 \%$ for each comorbidity $(p<0.01)$. Attending a visit was less strongly associated with BMI (aOR 1.18 for 35-39 versus 30-34, 95\% CI 1.09-1.27) and not at all with comorbidity. For the physician-level analysis, the adjusted probability of referral had a much wider range ( 0 to $83 \%$; mean $=19 \%$ ) than did the adjusted probability of attendance (range 27 to $34 \%$ ).

CONCLUSIONS: Few patients attended a weight management program. Physicians vary greatly in their probability of referring patients to programs but not in their patients' probability of attending.

J Gen Intern Med 36(8):2339-45

DOI: $10.1007 / \mathrm{s} 11606-020-06520-8$

(C) Society of General Internal Medicine 2021

Received July 14, 2020

Accepted December 20, 2020

Published online January 22, 2021

\section{BACKGROUND}

Obesity is a leading cause of preventable death ${ }^{1}$ and a contributor to the rising cost of care. ${ }^{2}$ Patients with obesity have greater health care expenditures, including for inpatient admissions, than patients who are of normal weight. ${ }^{3}$ Furthermore, longer duration of obesity increases the risk of poor health outcomes. Individuals who were obese at 25 years of age have significantly more preventable hospitalizations during their middle age years (age 45-64) than patients without longterm obesity even when accounting for current body mass index (BMI). ${ }^{4}$ Thus, supporting patients with obesity in their effort to attain and maintain a healthier weight is important for long-term population health.

Unfortunately, the percentage of patients who receive exercise or diet counseling has remained low for the past two decades. ${ }^{5,6}$ Based on a 2005 national survey, $18 \%$ of patients with a BMI $\geq 30 \mathrm{~kg} / \mathrm{m}^{2}$ received counseling on weight reduction. ${ }^{7}$ Physician beliefs ${ }^{8,9}$ and lack of training in nutrition ${ }^{10}$ may influence these discussions. For example, some physicians do not believe that obesity is a disease. ${ }^{9}$ One study found that $9 \%$ of physicians provided $52 \%$ of all weight counseling. ${ }^{8}$ Even physicians who want to address obesity may be limited by time constraints. ${ }^{11,12}$ To address obesity, health care systems should structure care in ways that support patients in their effort to attain and maintain a healthier weight.

One way to support patients is to facilitate weight management referrals, which are rare ${ }^{13}$ even when supported by best practice alerts. ${ }^{14}$ A pilot study found that electronic health record (EHR)-based alerts that included a list of clinic and community-based weight management programs had a minimal impact on referrals, ${ }^{15}$ suggesting that the problem is not physician awareness of treatment programs. Examining which patients receive referrals and, among those referred, which ones attend a weight management program, can provide insight into physician and patient behaviors so that health systems can develop structures to support the referral process. The primary objective of this study is to describe patient factors associated with referrals, which primarily reflect physician priorities, and attendance, which reflects patient 
priorities. We also examine physicians' influence by comparing adjusted rates of referral and attendance across physicians.

\section{METHODS}

\section{Study Population}

This retrospective cohort study included adults who had a primary care visit between 2015 and 2018 and a BMI $\geq 30$ $\mathrm{kg} / \mathrm{m}^{2}$. We excluded women who were pregnant or had been pregnant in the past year, and patients with cancer, because both conditions produce weight changes. Cleveland Clinic's Institutional Review Board approved this study.

\section{Referrals and Visits to Weight Management Programs}

Dates for referrals and visits to weight management programs were collected. We broadly defined weight management programs to include visits to dietitians, diabetic education, wellness programs that include weight loss, chronic disease management shared medical appointments for weight loss, bariatric medicine (including bariatric surgery) or cardiac rehabilitation, because these programs include education about nutrition and/or physical activity focusing on weight management. Patients could be referred more than once. For simplicity, we count each date a patient received a referral as a single referral opportunity (a.k.a. "referral"). Visits were required to occur within 180 days of the referral.

\section{Patient Characteristics}

Demographic characteristics (age, sex, race, marital status), smoking status, Charlson comorbidity score (and its component diseases) $)^{16}$, and insurance status were collected at the patient's initial visit. We created a binary variable combining married and living with a domestic partner versus all other statuses. We grouped insurance status into private, Medicare, Medicaid, and the Cleveland Clinic's employee health plan (EHP). Our EHP incentivizes employees and their spouses to participate in weight management and nutrition programs by waiving copays for certain programs and reducing their health insurance premiums the following year. Patients' weights and heights were collected from all visits within the health system during the study time period.

\section{Physician Identification}

We assigned each patient to their primary care provider as identified in our EHR system. Referrals to weight management programs were assigned to the primary care provider regardless of who made the referral (e.g., resident, nurse practitioner, other physician). To identify the impact of this assignment, we conducted a sensitivity analysis restricting the dataset to patients whose primary care provider made their referral.

\section{Statistical Analysis}

We used Student's $t$ test and chi-square test to compare the demographic and health characteristics of patients given referrals versus those who were not. Among patients who were referred, we compared those who attended a weight management program versus those who did not. Multilevel logistic regression models were used to identify the association between patient characteristics and (1) receiving a referral, and (2) attending a visit. The models included demographic and health characteristics and were adjusted for clustering within physician. We tested for an interaction effect between age and BMI. ${ }^{17}$ We plotted the adjusted predicted probability of receiving a referral or attending a visit by BMI category and decade of age. Secondarily, we repeated the regression analysis to identify individual comorbidities that were associated with receiving a referral or attending a visit.

To identify non-random variation in physician behavior, we identified each primary care physician's average probability of (1) offering a referral, and (2) having his or her patient attend a weight management visit. We did this by calculating each patient's individual adjusted probability of receiving a referral and attending a visit (for patients who received a referral). For each physician, we found his or her average probability across all of their patients. All analysis was conducted in Stata 14.0

\section{RESULTS}

Our sample included 160,163 adults who had a mean age of 50 years. Fifty-three percent were female and $77 \%$ were White. Median BMI was $35 \mathrm{~kg} / \mathrm{m}^{2}$, and $45 \%$ of patients had a score of greater than two on the Charlson comorbidity index.

\section{Patients Who Received a Referral to Weight Management}

Seventeen percent of patients received at least one referral to a weight management program during the study period, including $12 \%$ of patients with a BMI $30-34 \mathrm{~kg} / \mathrm{m}^{2}, 17 \%$ with a BMI $35-39 \mathrm{~kg} / \mathrm{m}^{2}$, and $31 \%$ with a BMI $\geq 40 \mathrm{~kg} / \mathrm{m}^{2}$ $(p<0.01)$. Patients who received a referral had a higher Charlson comorbidity score (3.1 versus 2.4 ) and higher BMI $\left(40 \mathrm{~kg} / \mathrm{m}^{2}\right.$ versus $\left.36 \mathrm{~kg} / \mathrm{m}^{2}\right)$ than those who did not $(p<0.01$ for all comparisons). There was a higher percentage of females (58\% versus 52\%), a lower percentage of White patients (66\% versus $78 \%$ ), and a lower percentage of married patients ( $46 \%$ versus $53 \%$ ) in the referral group ( $p<0.01$ for all comparisons). The adjusted odds of receiving a referral increased $47 \%$ for Black patients and $32 \%$ for each point on the Charlson comorbidity score ( $p$ $<0.01$ for all associations) (Table 1). The odds for referral were $15 \%$ lower for smokers compared to non-smokers $(p$ 
Table 1 Patient Characteristics of Those With and Without a Referral During the Study Period

\begin{tabular}{|c|c|c|c|c|}
\hline \multirow{2}{*}{$\begin{array}{l}\text { Patient } \\
\text { characteristics }\end{array}$} & \multirow{2}{*}{$\begin{array}{l}\text { No referral } \\
\text { Mean/ } \\
\text { percent }(N \\
=132,755)\end{array}$} & \multirow{2}{*}{$\begin{array}{l}\text { Referral } \\
\text { Mean/ } \\
\text { percent }(N \\
=27,312)\end{array}$} & \multirow[t]{2}{*}{ AOR* } & \multirow{2}{*}{$\begin{array}{l}95 \% \\
\text { CI }\end{array}$} \\
\hline & & & & \\
\hline Age** & 49.4 & 50.2 & 0.80 & $\begin{array}{l}0.79 \\
0.82\end{array}$ \\
\hline $\begin{array}{l}\text { Female (versus } \\
\text { male) }\end{array}$ & $52 \%$ & $58 \%$ & 1.05 & $\begin{array}{l}1.01- \\
1.08\end{array}$ \\
\hline White race & $78 \%$ & $66 \%$ & - & - \\
\hline $\begin{array}{l}\text { Black race (versus } \\
\text { White) }\end{array}$ & $16 \%$ & $28 \%$ & 1.47 & $\begin{array}{l}1.41- \\
1.54\end{array}$ \\
\hline $\begin{array}{l}\text { Married (versus } \\
\text { non-Married) }\end{array}$ & $53 \%$ & $46 \%$ & 0.98 & $\begin{array}{l}0.95- \\
1.01\end{array}$ \\
\hline $\begin{array}{l}\text { Smoker (versus } \\
\text { non-smoker) }\end{array}$ & $15 \%$ & $14 \%$ & 0.85 & $\begin{array}{l}0.81- \\
0.88\end{array}$ \\
\hline $\begin{array}{l}\text { Age-adjusted } \\
\text { Charlson } \\
\text { comorbidity score } \\
* *\end{array}$ & 2.40 & 3.11 & 1.32 & $\begin{array}{l}1.31- \\
1.34\end{array}$ \\
\hline \multicolumn{5}{|l|}{ BMI Category } \\
\hline $30-34$ & $56 \%$ & $35 \%$ & - & - \\
\hline $\begin{array}{l}35-39 \text { (versus } \\
30-34 \text { ) }\end{array}$ & $26 \%$ & $26 \%$ & 1.57 & $\begin{array}{l}1.52- \\
1.63\end{array}$ \\
\hline 34$) \geq 40($ versus $30-$ & $18 \%$ & $39 \%$ & 3.48 & $\begin{array}{l}3.36- \\
3.60\end{array}$ \\
\hline \multicolumn{5}{|l|}{ Insurance } \\
\hline Private & $62 \%$ & $51 \%$ & - & - \\
\hline $\begin{array}{l}\text { Employee health } \\
\text { plan (versus } \\
\text { private) }\end{array}$ & $5 \%$ & $7 \%$ & 1.28 & $\begin{array}{l}1.21- \\
1.36\end{array}$ \\
\hline $\begin{array}{l}\text { Medicare (versus } \\
\text { private) }\end{array}$ & $18 \%$ & $22 \%$ & 1.08 & $\begin{array}{l}1.04- \\
1.14\end{array}$ \\
\hline $\begin{array}{l}\text { Medicaid (versus } \\
\text { private) }\end{array}$ & $15 \%$ & $20 \%$ & 1.41 & $\begin{array}{l}1.35- \\
1.47\end{array}$ \\
\hline
\end{tabular}

*A multilevel regression model was used to identify the association between receiving a referral or not. The model was adjusted for patient demographic and health characteristics and clustering within physician. The model also included the year a person first appeared in the dataset. All values are statistically significant at $p<0.01$

**Age is reported in years; AOR is reported for every 10 years increase in age

$<0.01)$. The adjusted probability of receiving a referral declined with age, but at every age, patients with a higher BMI were more likely to be referred (Fig. 1a).

\section{Weight Management Visits After Referral}

Twenty-nine percent of patients who received a referral had a subsequent weight management visit. Patients who attended a visit had more prior referrals than patients who never attended (1.83 versus $1.75, p<0.01)$. The mean number of days between the last referral and visit was 32. Compared to patients who did not attend, those who attended were slightly younger (49 versus 51 years), more likely to be female $(61 \%$ versus $56 \%)$, and to be married ( $49 \%$ versus $44 \%)(p<0.01$ for all comparisons). The adjusted odds of having a visit increased 19\% for females, $27 \%$ for Black patients, and $17 \%$ for married patients $(p<0.01)$. They were $45 \%$ lower for smokers compared to non-smokers $(p<0.01)$. Patients with a BMI $\geq 35$ were significantly more likely to attend than patients with a BMI 30-34 (AOR 1.18, 95\% CI 1.09-1.27 for patients with a BMI 35-39; AOR 1.27, 95\% CI 1.18-1.35 for patients with a $B M I \geq 40)$. Charlson comorbidity score was not associated with attendance $(p=0.33)$ (Table 2). As seen in Fig. $1 b$, the probability of attending a visit declined with age and lower BMI, but the slope of decline was not nearly as pronounced as it was for referrals.

\section{Physician Effect on Referrals and Visits}

Almost all physicians (99\%) provided $\geq 1$ referral. Twentypercent of the physicians $(n=131)$ made half of the referrals. As seen in Fig. 2a, the adjusted probability of a physician referring their patient to weight management ranged from 0 to $83 \%$, with a mean of $19 \%$. For physicians who made referrals, the average adjusted probability of a patient attending a weight management visit was $31 \%$ (range 27 to 34\%) (Fig. 2b). In our sensitivity analysis that was restricted to physicians who referred their primary care patients to weight management, the average predicted probability of a patient attending a visit was slightly lower $27 \%$ (range $0.23-0.31$ ).

\section{Secondary Analysis}

Patients who have diabetes had significantly higher odds of receiving a referral (AOR 4.37, 95\% CI 3.94-4.84) and attending a visit (AOR 1.23, 95\% CI 1.01-1.50) than did patients without diabetes. (Appendix Table 3)

\section{DISCUSSION}

In our study of over 160,000 primary care patients with obesity, only a small percentage received a referral to weight management. Patients with more comorbidities and more severe obesity were more likely to receive a referral, as were younger patients. Of patients who did receive a referral, less than a third attended a visit within 6 months. Degree of obesity, but not number of comorbidities, was significantly related to attending a visit. Physician's propensity to refer patients differed drastically but not their patients' probability of attending a visit. Taken together, these results suggest that if physicians referred more patients to weight management programs, more patients would attend.

Our study is one of the first to examine the rates of referrals to weight management programs and subsequent attendance. Since weight management tools are an integral part of many programs, we took a broad view, focusing on referrals to a variety of therapeutic interventions. Thus, we found a higher percentage of referrals than other studies. A cohort study of primary care patients in the United Kingdom (UK) found that $6 \%$ of patients with a BMI $30-34,10 \%$ of patients with a BMI $35-39$, and $17 \%$ of patients with a BMI $\geq 40$ received a referral to dieticians, exercise therapy, or weight management programs. ${ }^{18}$ Our referral rate was almost double that $12 \%$ for patients with a BMI $30-34,17 \%$ for patients with a BMI 


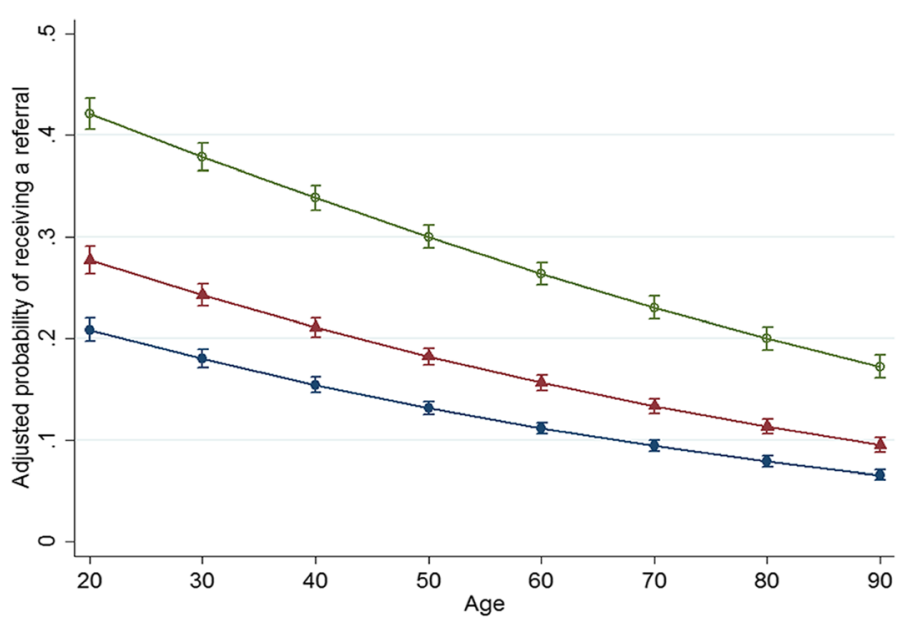

b

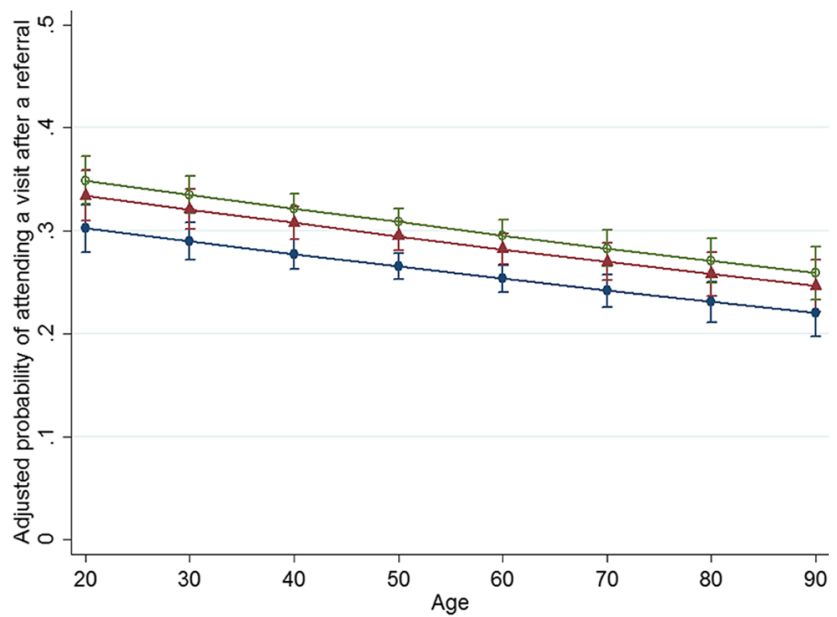

Figure 1 Patient's adjusted probability of being offered a referral (a) and attending a weight management visit (b).

Table 2 Characteristics of Patients With and Without a Visit After a Referral

\begin{tabular}{|c|c|c|c|c|}
\hline \multirow[t]{2}{*}{$\begin{array}{l}\text { Patient } \\
\text { characteristics }\end{array}$} & \multirow{2}{*}{$\begin{array}{l}\begin{array}{l}\text { No visit } \\
\text { after } \\
\text { referral }\end{array} \\
\text { Mean/ } \\
\text { percent ( } N \\
=19,327)\end{array}$} & \multirow{2}{*}{$\begin{array}{l}\begin{array}{l}\text { Visit after } \\
\text { referral }\end{array} \\
\text { Mean/ } \\
\text { percent }(N \\
=7,985)\end{array}$} & \multirow[t]{2}{*}{ AOR* } & \multirow[t]{2}{*}{$\begin{array}{l}95 \% \\
\text { CI }\end{array}$} \\
\hline & & & & \\
\hline Age** $^{* *}$ & 50.8 & 48.7 & 0.93 & $\begin{array}{l}0.90 \\
0.96\end{array}$ \\
\hline $\begin{array}{l}\text { Female (versus } \\
\text { male) }\end{array}$ & $56 \%$ & $61 \%$ & 1.19 & $\begin{array}{l}1.13- \\
1.27\end{array}$ \\
\hline White race & $68 \%$ & $62 \%$ & - & - \\
\hline $\begin{array}{l}\text { Black race (versus } \\
\text { White) }\end{array}$ & $26 \%$ & $32 \%$ & 1.27 & $\begin{array}{l}1.18- \\
1.36\end{array}$ \\
\hline $\begin{array}{l}\text { Married (versus } \\
\text { non-married) }\end{array}$ & $44 \%$ & $49 \%$ & 1.17 & $\begin{array}{l}1.10- \\
1.24\end{array}$ \\
\hline $\begin{array}{l}\text { Smoker (versus } \\
\text { non-smoker) }\end{array}$ & $16 \%$ & $9 \%$ & 0.55 & $\begin{array}{l}0.50 \\
0.61\end{array}$ \\
\hline $\begin{array}{l}\text { Age-adjusted } \\
\text { Charlson } \\
\text { comorbidity } \\
\text { score** }\end{array}$ & 3.2 & 2.9 & 1.01 & $\begin{array}{l}0.99- \\
1.03\end{array}$ \\
\hline $\begin{array}{l}\text { BMI category } \\
\quad 30-34\end{array}$ & $37 \%$ & $32 \%$ & - & - \\
\hline $35-39$ & $26 \%$ & $26 \%$ & 1.18 & $\begin{array}{l}1.09 \\
1.27\end{array}$ \\
\hline$\geq 40$ & $37 \%$ & $42 \%$ & 1.27 & $\begin{array}{l}1.18 \\
1.35\end{array}$ \\
\hline $\begin{array}{l}\text { Insurance } \\
\text { Private }\end{array}$ & & & & \\
\hline $\begin{array}{l}\text { Employee health } \\
\text { plan (versus } \\
\text { private) }\end{array}$ & $\begin{array}{l}01 \% \\
6 \%\end{array}$ & $\begin{array}{l}60 \% \\
13 \%\end{array}$ & 1.91 & $\begin{array}{l}- \\
1.72- \\
2.11\end{array}$ \\
\hline $\begin{array}{c}\text { Medicare } \\
\text { (versus private) }\end{array}$ & $10 \%$ & $10 \%$ & 0.79 & $\begin{array}{l}0.72- \\
0.86\end{array}$ \\
\hline $\begin{array}{c}\text { Medicaid } \\
\text { (versus private) }\end{array}$ & $23 \%$ & $17 \%$ & 0.84 & $\begin{array}{l}0.77- \\
0.91\end{array}$ \\
\hline
\end{tabular}

*A multilevel regression model was used to identify the association between receiving a referral and attending a visit within 180 days versus not. The model was adjusted for patient demographic and health characteristics and clustering within physician. The model also included the year a person appeared in the dataset. The population was limited to patients who received at least one referral

**Age is reported in years; AOR is reported for every 10 years increase in age category $35-39$, and $31 \%$ for patients with a BMI $\geq 40$. Our higher rate of referrals may be due to our more recent study period (the UK study enrolled patients between 2005 and 2012), which follows the American Medical Association's decision to classify obesity as a disease in 2013. Our referral rate was marginally higher than a study which placed electronic alerts into the charts of family practice patients who had a BMI indicative of obesity, suggesting that EHR alerts alone will not increase referrals to weight management. ${ }^{14}$

Several patient characteristics were associated with receiving a referral. Patients who were female, Black, had a higher Charlson comorbidity score or had a BMI greater than 34 had higher adjusted odds of receiving a referral. Prior research has found similar predictors for various referrals: female patients were more likely to be referred to weight management program in a community health center, ${ }^{19}$ Black patients were more likely to be referred to diabetes education, ${ }^{20}$ patients who received a physician-based referral to weight management had more chronic conditions than patients who selfreferred, ${ }^{21}$ and patients with obesity were more likely to be referred to weight management. ${ }^{18}$ Patients who had Medicaid or Medicare insurance or were part of Cleveland Clinic's employee health plan had higher odds of receiving a referral than patients with commercial insurance. We found that older age and smoking were associated with reduced odds of receiving a referral. Physicians may be reluctant to promote weight loss in older adults due to the obesity paradox, ${ }^{22}$ or believe that older adults and smokers are unlikely to change their habits. In fact, older patients and smokers were less likely to attend a visit if they were referred. However, obesity and smoking are both associated with adverse events among older adults and require appropriate mitigation. ${ }^{22,23}$ Patients who plan to quit smoking, which may be accompanied by weight gain, ${ }^{24}$ may particularly benefit from a weight management program. Ultimately, these characteristics are a reflection of both 

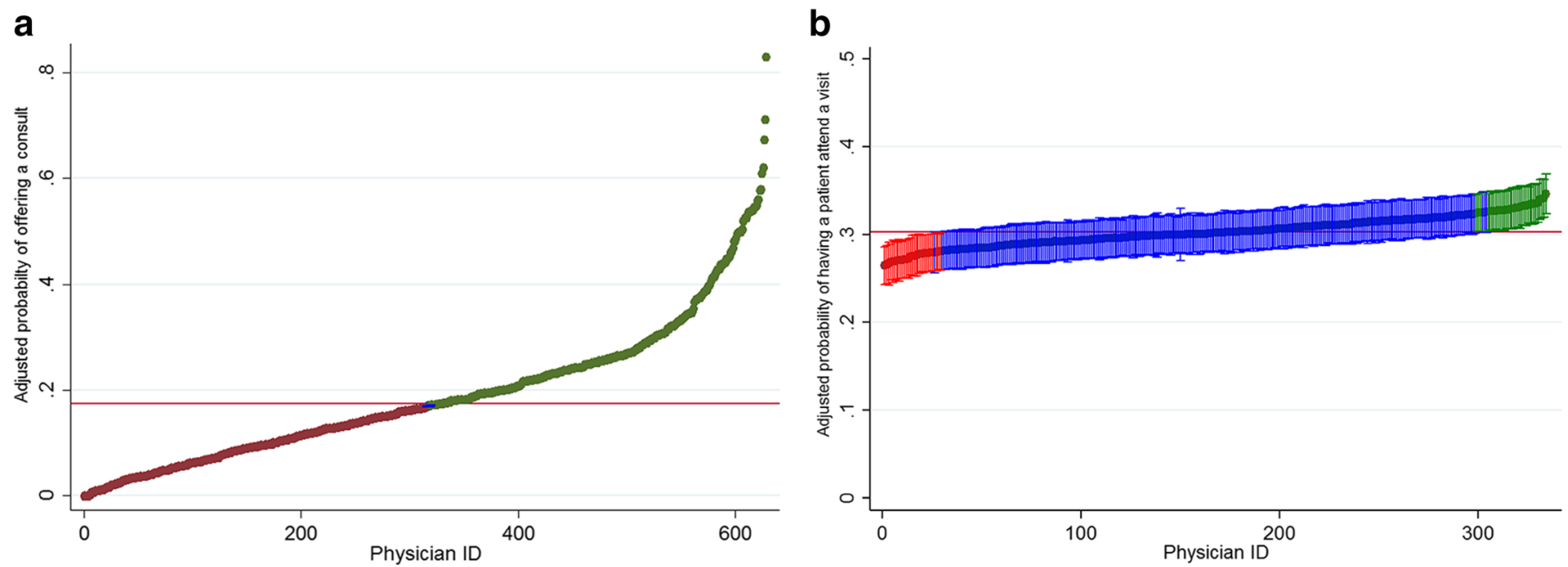

Figure 2 Physician's adjusted probability of offering a patient a referral (a) and having a patient attend a visit (b). The horizontal line represents the mean for all patients. Dots represent the point estimate and whiskers represent the $95 \%$ confidence intervals. Blue dots are not different from the mean, green dots are statistically significantly higher, and red dots significantly lower than the mean.

physicians' views on who needs a referral as well as patients' desire to receive one, since referrals are ideally made after an open and respectful discussion.

Once the referral is placed, the decision to attend rests with the patient. Some, but not all, characteristics associated with a referral were also associated with attending a visit. Being Black, female, and having a BMI of $35 \mathrm{~kg} / \mathrm{m}^{2}$ or over or EHP insurance (versus private) were all associated with attending a visit. Age and Charlson comorbidity score were not. A study of attendance at a weight management service in the UK likewise found that women and patients with a BMI $\geq 35$ $\mathrm{kg} / \mathrm{m}^{2}$ had higher odds of attending, but they also found that patients $\geq 65$ were more likely to attend a visit than patients 18-24 years of age. ${ }^{25}$ Patients who had Medicare or Medicaid insurance had reduced odds of attending a visit. Nationally, only $0.2 \%$ of Medicare patients used Medicare's intensive behavioral therapy benefit ${ }^{26}$ which supports behavioral counseling and therapy by a primary care practitioner in a primary care setting. ${ }^{27}$ Importantly, patients' who have experienced health care-based weight stigmatization may avoid clinical care, including weight management programs ${ }^{28}$ highlighting the importance of a respectful discussion during the clinical visit on uptake of future care.

The interaction between insurance, weight management referrals, and attendance has not been explored previously within the general population of adults with obesity. Patients with private insurance were least likely to receive a referral, but more likely to attend a visit than patients with Medicare or Medicaid. Inconsistent coverage for nutritional visits across Medicaid programs,${ }^{29}$ and the requirement for comorbidities such as diabetes in Medicare programs, $\left[{ }^{25,28,30}\right]$ may play a role. Patients with private insurance may be less willing to accept a referral unless they know their insurance will cover it. We found that patients with our EHP were both more likely to be referred and more likely to attend, which may reflect the reduced copays for some programs and financial incentives for weight loss in the form of reduced insurance premiums.

Physicians' adjusted probability of referring patients ranged from 0 to $83 \%$. This substantial variation suggests that it is driven by physicians' preferences. Physicians who report system barriers (e.g., lack of time) or believe that counseling is ineffective are less likely to report discussing physical activity with most of their at-risk patients. ${ }^{31}$ Physicians who themselves have a normal BMI (18-25) discussed weight loss more often than physicians who are overweight or obese. ${ }^{32}$ Furthermore, we found that the range of attendance rates across physicians was much narrower than the range of referrals. Not surprisingly, physician preferences have much less influence over attendance. Together, these findings suggest that if physicians were simply to refer more often, more of their patients would attend a weight management program.

As people age, they are at increased risk of developing obesity and its resultant comorbidities. ${ }^{17,33}$ Once an individual develops obesity, the likelihood of attaining a normal BMI is low and it is even lower among individuals who have a BMI $\geq$ $40 .^{34}$ Thus, it is imperative that physicians address obesity at lower BMIs (e.g., 30-34) and before patients acquire other chronic conditions (e.g., diabetes, hypertension). Unfortunately, we found that physicians appeared to wait until patients reached higher levels of obesity and/or developed comorbid conditions. Although patients were also more likely to attend visits if they had BMI $>40$, the magnitude of this effect was quite small $(\mathrm{AOR}=1.27)$ compared to the effect on referrals $(\mathrm{AOR}=3.48)$.

Another reason for early referral is that it may take several conversations before a patient agrees to a visit. We found that patients who received a referral averaged at least two, and those who attended a weight management program received 
more referrals than those who did not attend. A study based on the National Health and Nutrition Examination survey found that $19 \%$ of patients with obesity did not consider themselves to be overweight or have obesity; this number drops to $3 \%$ if a physician had informed the patient he/she had been overweight. ${ }^{35}$ Black and Hispanic patients may have particular difficulty identifying their obesity, especially at lower levels. ${ }^{36}$ Discussions of weight loss within the visit may be a starting point, but there is a dose-based relationship between receiving more counseling sessions and weight loss. ${ }^{37}$ Furthermore, at least one study found that meeting with a lifestyle coach helped to promote sustained weight loss. ${ }^{38}$

\section{Limitations}

Our study has limitations. We used a commonly accepted indicator of obesity, BMI $\geq 30 \mathrm{~kg} / \mathrm{m}^{2}$, as part of our inclusion criteria. Since BMI is an imperfect measure of excess weight, not all patients in our dataset necessarily have excess adiposity. Second, we did not capture discussions of weight loss or physical activity. Patients may have followed diet and lifestyle advice from their clinicians and attended gyms or commercial weight loss programs. However, the extreme variation among physicians is unlikely to be due to unmeasured interventions. There has been prior research on discussions of weight loss; our goal was to understand how patients interacted with weight management programs within the health system. Finally, we could not account for patients' past experiences of weight loss programs on physicians' attitudes towards weight loss interventions. A strength of our study was our large sample comprising multiple years of data.

\section{CONCLUSIONS}

In our large integrated health system, we found that rates of referrals to weight management programs were low and most patients who were referred did not attend. Physicians vary greatly in their probability of referring patients to programs but not in their patients' probability of attending. The high rates of referral by some physicians indicate that referrals are acceptable to patients and that physicians are primarily responsible for the low referral rates. Presumably, referring more patients would result in more visits and greater weight loss.

Corresponding Author: Elizabeth R. Pfoh, PhD, MPH; Center for Value-Based Care Research, Cleveland Clinic Community Care, Cleveland, OH, USA (e-mail: pfohe@ccf.org).

Funding This study was supported by a Healthcare Delivery and Implementation Science Center grant. Dr. Pfoh's time is supported by a NIH loan repayment grant from NHLBI. No other funding supported this work.

\section{Compliance with Ethical Standards:}

Conflict of Interest: Dr. Pfoh's time was supported by a Healthcare Delivery and Implementation Science Center grant. No other funding supported this work. All authors report that they have no financial relationships with commercial associations that may pose a conflict of interest with the reported work.

Supplementary Information The online version contains supplementary material available at https://doi.org/10.1007/s11606-02006520-8.

\section{REFERENCES}

1. Peeters A, Barendregt JJ, Willekens F, et al. Obesity in Adulthood and Its Consequences for Life Expectancy: A Life-Table Analysis. Ann Intern Med. 2003;138(1):24. doi:https://doi.org/10.7326/0003-4819-138-1200301070-00008

2. Finkelstein EA, Trogdon JG, Cohen JW, Dietz W. Annual Medical Spending Attributable To Obesity: Payer-And Service-Specific Estimates: Amid calls for health reform, real cost savings are more likely to be achieved through reducing obesity and related risk factors. Health Aff (Millwood). 2009;28(Supplement 1):w822-w831. doi:https://doi.org/10. 1377/hlthaff.28.5.w822

3. Musich S, MacLeod S, Bhattarai GR, et al. The Impact of Obesity on Health Care Utilization and Expenditures in a Medicare Supplement Population. Gerontol Geriatr Med. 2016;2:233372141562200. doi:https://doi.org/10.1177/2333721415622004

4. Schafer MH, Ferraro KF. Long-term obesity and avoidable hospitalization among younger, middle-aged, and older adults. Arch Intern Med. 2007;167(20):2220-2225. doi:https://doi.org/10.1001/archinte.167.20. 2220

5. Kraschnewski JL, Sciamanna CN, Stuckey HL, et al. A silent response to the obesity epidemic: decline in US physician weight counseling. Med Care. 2013;51(2):186-192. doi:https://doi.org/10.1097/MLR. Ob013e3182726c33

6. Ciciurkaite G, Moloney ME, Brown RL. The Incomplete Medicalization of Obesity: Physician Office Visits, Diagnoses, and Treatments, 19962014. Public Health Rep Wash DC 1974. 2019;134(2):141-149. doi:https://doi.org/10.1177/0033354918813102

7. Bleich SN, Pickett-Blakely O, Cooper LA. Physician practice patterns of obesity diagnosis and weight-related counseling. Patient Educ Couns. 2011;82(1):123-129. doi:https://doi.org/10.1016/j.pec.2010.02.018

8. Kraschnewski JL, Sciamanna CN, Pollak KI, Stuckey HL, Sherwood NE. The epidemiology of weight counseling for adults in the United States: a case of positive deviance. Int J Obes 2005. 2013;37(5):751-753. doi:https://doi.org/10.1038/ijo.2012.113

9. Funk LM, Jolles SA, Voils CI. Obesity as a disease: has the AMA resolution had an impact on how physicians view obesity? Surg Obes Relat Dis Off J Am Soc Bariatr Surg. 2016;12(7):1431-1435. doi:https:// doi.org/10.1016/j.soard.2016.05.009

10. Vetter ML, Herring SJ, Sood M, Shah NR, Kalet AL. What do resident physicians know about nutrition? An evaluation of attitudes, selfperceived proficiency and knowledge. J Am Coll Nutr. 2008;27(2):287298. doi:https://doi.org/10.1080/07315724.2008.10719702

11. Glenister KM, Malatzky CA, Wright J. Barriers to effective conversations regarding overweight and obesity in regional Victoria. Aust Fam Physician. 2017;46(10):769-773.

12. Jung FUCE, Luck-Sikorski C, König H-H, Riedel-Heller SG. Stigma and Knowledge as Determinants of Recommendation and Referral Behavior of General Practitioners and Internists. Obes Surg. 2016;26(10):2393-2401. doi:https://doi.org/10.1007/s11695-0162104-5

13. Kushner RF, Ryan DH. Assessment and lifestyle management of patients with obesity: clinical recommendations from systematic reviews. JAMA. 2014;312(9):943-952. doi:https://doi.org/10.1001/jama.2014.10432 
14. Schriefer SP, Landis SE, Turbow DJ, Patch SC. Effect of a computerized body mass index prompt on diagnosis and treatment of adult obesity. Fam Med. 2009;41(7):502-507.

15. Fitzpatrick SL, Dickins K, Avery E, et al. Effect of an obesity best practice alert on physician documentation and referral practices. Trans Behav Med. 2017;7(4):881-890. doi:https://doi.org/10.1007/s13142017-0514-0

16. Austin SR, Wong Y-N, Uzzo RG, Beck JR, Egleston BL. Why Summary Comorbidity Measures Such As the Charlson Comorbidity Index and Elixhauser Score Work. Med Care. 2015;53(9):e65-72. doi:https://doi. org/10.1097/MLR.0b013e318297429c

17. Hruby A, Manson JE, Qi L, et al. Determinants and Consequences of Obesity. Am J Public Health. 2016;106(9):1656-1662. doi:https://doi. org/10.2105/AJPH.2016.303326

18. Booth HP, Prevost AT, Gulliford MC. Access to weight reduction interventions for overweight and obese patients in UK primary care: population-based cohort study. BMJ Open. 2015;5(1):e006642. doi:https://doi.org/10.1136/bmjopen-2014-006642

19. Daniel Clark, Lisa Chrysler, Anthony Perkins, et al. Screening Referral, and Participation in a Weight Management Program Implemented in Five CHCs. J Health Care Poor Underserved. 2010;21(2):617628. doi:https://doi.org/10.1353/hpu.0.0319

20. Hooks-Anderson DR, Crannage EF, Salas J, Scherrer JF. Race and referral to diabetes education in primary care patients with prediabetes and diabetes. Diabetes Educ. 2015;41(3):281-289. doi:https://doi.org/ $10.1177 / 0145721715574604$

21. Binks M, O'Neil MP. Referral sources to a weight management program: relation to outcome. J Gen Intern Med. 2002;17(8):596-603. doi:https:// doi.org/10.1046/j.1525-1497.2002.11028.x

22. Murphy CM, Rohsenow DJ, Johnson KC, Wing RR. Smoking and weight loss among smokers with overweight and obesity in Look AHEAD. Health Psychol Off J Div Health Psychol Am Psychol Assoc. 2018;37(5):399-406. doi:https://doi.org/10.1037/hea0000607

23. Henley SJ, Asman K, Momin B, et al. Smoking cessation behaviors among older U.S. adults. Prev Med Rep. 2019;16:100978. https://doi. org/10.1016/j.pmedr.2019.100978

24. Bush T, Lovejoy JC, Deprey M, Carpenter KM. The effect of tobacco cessation on weight gain, obesity, and diabetes risk. Obes Silver Spring Md. 2016;24(9):1834-1841. doi:https://doi.org/10.1002/oby.21582

25. Blane DN, McLoone P, Morrison D, Macdonald S, O'Donnell CA Patient and practice characteristics predicting attendance and completion at a specialist weight management service in the UK: a crosssectional study. BMJ Open. 2017;7(11):e018286. doi:https://doi.org/10. 1136/bmjopen-2017-018286

26. Dewar S, Bynum J, Batsis JA. Uptake of Obesity Intensive Behavioral Treatment Codes in Medicare Beneficiaries, 2012-2015. J Gen Intern Med. 2020;35(1):368-370. doi:https://doi.org/10.1007/s11606-01905437-1
27. Centers for Medicare and Medicaid Services. Decision Memo for Intensive Behavioral Therapy for Obesity (CAG-00423 N). Published November 29, 2011. https://www.cms.gov/medicare-coverage-database/details/ncadecision-memo.aspx?NCAId $=253$

28. Phelan SM, Burgess DJ, Yeazel MW, Hellerstedt WL, Griffin JM, Ryn M. Impact of weight bias and stigma on quality of care and outcomes for patients with obesity. Obes Rev. 2015;16(4):319-326. doi:https://doi.org/ 10.1111/obr. 12266

29. Jannah N, Hild J, Gallagher C, Dietz W. Coverage for Obesity Prevention and Treatment Services: Analysis of Medicaid and State Employee Health Insurance Programs: State Coverage of Obesity Services. Obesity. 2018;26(12):1834-1840. doi:https://doi.org/10.1002/oby.22307

30. Nutrition therapy services. https://www.medicare.gov/coverage/nutri tion-therapy-services

31. Omura JD, Bellissimo MP, Watson KB, Loustalot F, Fulton JE, Carlson SA. Primary care providers' physical activity counseling and referral practices and barriers for cardiovascular disease prevention. Prev Med. 2018;108:115-122. doi:https://doi.org/10.1016/j.ypmed.2017.12. 030

32. Bleich SN, Bennett WL, Gudzune KA, Cooper LA. Impact of physician BMI on obesity care and beliefs. Obes Silver Spring Md. 2012;20(5):9991005. doi:https://doi.org/10.1038/oby.2011.402

33. GBD 2015 Obesity Collaborators, Afshin A, Forouzanfar MH, et al. Health Effects of Overweight and Obesity in 195 Countries over 25 Years. N Engl J Med. 2017;377(1):13-27. https://doi.org/10.1056/NEJMoa1614362

34. Fildes A, Charlton J, Rudisill C, Littlejohns P, Prevost AT, Gulliford MC. Probability of an Obese Person Attaining Normal Body Weight: Cohort Study Using Electronic Health Records. Am J Public Health. 2015;105(9):e54-e59. doi:https://doi.org/10.2105/AJPH.2015.302773

35. Post RE, Mainous AG, Gregorie SH, Knoll ME, Diaz VA, Saxena SK. The Influence of Physician Acknowledgment of Patients' Weight Status on Patient Perceptions of Overweight and Obesity in the United States. Arch Intern Med. 2011;171(4). https://doi.org/10.1001/archinternmed.2010.549

36. Sivalingam SK, Ashraf J, Vallurupalli N, Friderici J, Cook J, Rothberg MB. Ethnic Differences in the Self-Recognition of Obesity and ObesityRelated Comorbidities: A Cross-Sectional Analysis. J Gen Intern Med. 2011;26(6):616-620. doi:https://doi.org/10.1007/s11606-010-1623-3

37. Wadden TA, Butryn ML, Hong PS, Tsai AG. Behavioral Treatment of Obesity in Patients Encountered in Primary Care Settings: A Systematic Review. JAMA. 2014;312(17):1779. doi:https://doi.org/10.1001/jama. 2014.14173

38. Kumanyika SK, Fassbender JE, Sarwer DB, et al. One-year results of the Think Health! study of weight management in primary care practices. Obes Silver Spring Md. 2012;20(6):1249-1257. doi:https://doi.org/10. 1038/oby.2011.329

Publisher's Note: Springer Nature remains neutral with regard to jurisdictional claims in published maps and institutional affiliations. 